\title{
Surgical Treatment of a Subtrochanteric Pseudarthrosis in a 5 Year-Old Child at the University Hospital of Tingandogo in Burkina Faso
}

\author{
Anatole Jean Innocent Ouedraogo ${ }^{*}$, Oumar Salia ${ }^{1}$, Sayouba Tinto ${ }^{2}$, Alexandre Stanislas Korsaga ${ }^{2}$, \\ Ningwende Paul Fernand Ouedraogo', Anselme Noaga Nikiema1, Namori Keita ${ }^{2}$, \\ Hamado Kafando'2, Mamoudou Sawadogo², Songahir Christophe Da²
}

${ }^{1}$ Unit of Traumatology and Orthopedics, Tingandogo University Hospital, Ouagadougou, Burkina Faso

${ }^{2}$ Department of Traumatology and Orthopedics, Yalgado Ouedraogo University Hospital, Ouagadougou, Burkina Faso

Email: *anatoleji2001@yahoo.fr

How to cite this paper: Ouedraogo, A.J.I., Salia, O., Tinto, S., Korsaga, A.S., Ouedraogo, N.P.F., Nikiema, A.N., Keita, N., Kafando, H., Sawadogo, M. and Da, S.C. (2019) Surgical Treatment of a Subtrochanteric Pseudarthrosis in a 5 Year-Old Child at the University Hospital of Tingandogo in Burkina Faso. Open Journal of Orthopedics, 9, 225-230.

https://doi.org/10.4236/ojo.2019.911023

Received: September 13, 2019

Accepted: November 1, 2019

Published: November 4, 2019

Copyright $\odot 2019$ by author(s) and Scientific Research Publishing Inc. This work is licensed under the Creative Commons Attribution International License (CC BY 4.0).

http://creativecommons.org/licenses/by/4.0/

\section{c) (i) Open Access}

\begin{abstract}
The subtrochanteric fractures are relatively rare in the child and they constitute a therapeutic problem. The pseudarthrosis of this fracture in the child is often the complication of a subtrochanteric fracture treated orthopedically. We report the case of a subtrochanteric pseudarthrosis in a 5 year-old child occurred following an orthopedic treatment. After surgical treatment by bloody reduction and pinning, the pseudarthrosis consolidated in 10 months with satisfactory functional results.
\end{abstract}

\section{Keywords \\ Pseudarthrosis, Sub-Trochanter, Child, Surgery}

\section{Introduction}

The hip fractures in the child are rare and represent less than $1 \%$ of the fractures as a whole [1] [2]. The subtrochanteric fractures constitute a real therapeutic problem because, on the one hand, it is an area which is subjected to strong pressures due to insertions of powerful muscles which actions facilitate the displacement of the fracture and make difficult an anatomical reduction and, on the other hand, because of the small size of the proximal fragment. Fortunately, the subtrochanteric fractures are relatively rare in the children, with an incidence from $4 \%$ to $10 \%$ of the fractures of the femur as a whole [3] [4]. The usual 
treatment of subtrochanteric fractures of the child is orthopedic [2], surgery being the last option. The usual complications of the fractures of the child can appear as of the 6th week of the traumatism, but, the pseudarthrosis is rare because of the enormous potential of osseous consolidation [2] [3] [4] [5]. The orthopedic treatment of the subtrochanteric fracture of the child can lead to pseudarthrosis like in the case of our patient. We justify this work to show the interest of the surgical management of the subtrochanteric fractures in the child in order to obtain a good therapeutic result.

\section{Observation}

A 5 year-old patient, pupil in the pre-school, without known pathological history, has been received at 6 months of a trauma of the right hip and the right hand as a result of a road accident, an automobile impact against a motorbike. The mechanism is not specified, the patient sitting on the luggage-rack of a motorbike. The initial orthopedic management was made in a health facility of the area: right brachio-ante-brachio-palmar plaster for locked fracture of the proximal third of the humeral diaphysis and stuck traction of the right pelvic limb on splint of Boppe during 21 days followed with a pelvic-pedaling plaster during 45 days for closed subtrochanteric fracture. The humeral fracture evolved towards an osseous consolidation.

The clinical examination finds a painful mobility of the femoral fracture siteprohibiting walking, a vicious attitude in flexum of $10^{\circ}$ of the right knee, an amyotrophy of the right thigh of $3 \mathrm{~cm}$, a shortening of the right pelvic limb of $3 \mathrm{~cm}$. The radiographic review (Figure 1) objectifies an absence of consolidation of the fracture.

It was indicated and carried out in this patient a bloody reduction and stabilization by two pins of Kirschner diameter $2.2 \mathrm{~mm}$ placed under scopic control. A lateral approach in subtrochanteric area has been used for the reduction; then an osseous trepanation at $5 \mathrm{~cm}$ approximately of the lateral condyle of the right femur allowed the pins of Kirschner to be placed retrograde to the femoral neck under scopic control. After the reintegration of the lateral vast muscle and

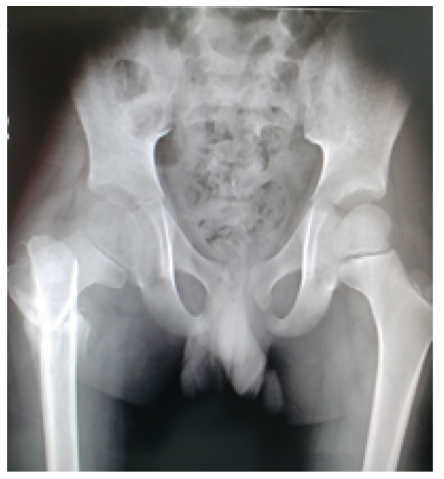

(a)

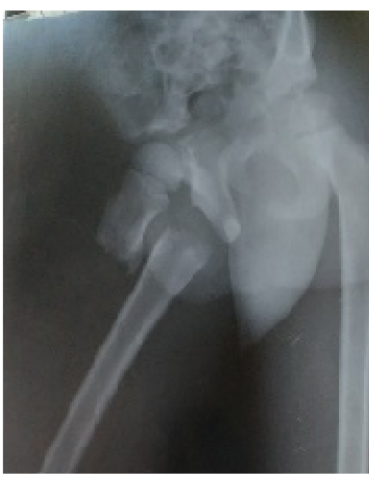

(b)

Figure 1. Front and profile $\mathrm{x}$-ray views showing the subtrochanteric pseudarthrosis. (a) Front view; (b) Profileview. 
setting up a discharge pipe, the suture has been made tissue by tissue. These pins were first curved and cut. A pelvic-pedaling plaster was set up for 45 days, followed with nursing. Postoperatives follow-ups were simple. Progressive loading was authorized from 45th postoperative day after removal of the pelvic-pedaling plaster. This resumption of walking has been supervised by 15 sessions of functional rehabilitation. The patient was regularly re-examined every month with control $\mathrm{x}$-rays. Ten months after the surgical procedure, the $\mathrm{x}$-rays showed a solid and homogeneous bone healing callus (Figure 2).

The recovery of the function of the pelvic right limb was satisfactory: visible ability to walk without pain (Figure 3), long iso limbs (Figure 4), disappearance of the flexum, flexion of the knee at $100^{\circ}$. An ablation of the pins is considered.

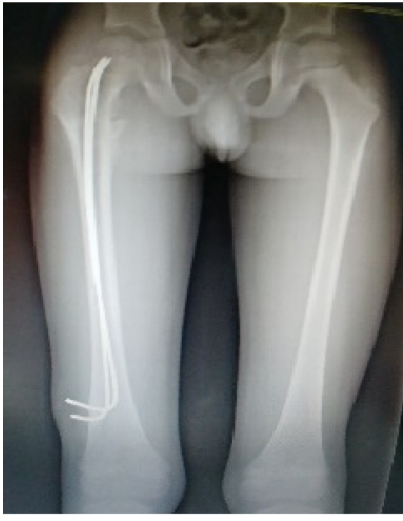

(a)

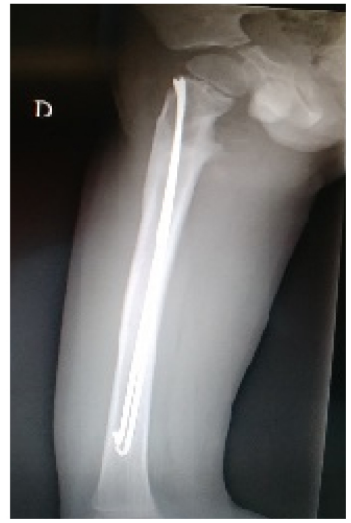

(b)

Figure 2. Front and profile views showing a callus homogeneous. (a) Front view; (b) Profile view.

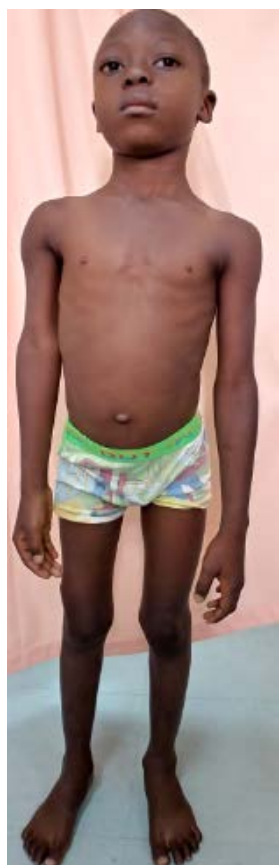

Figure 3. Satisfactory walking ability. 


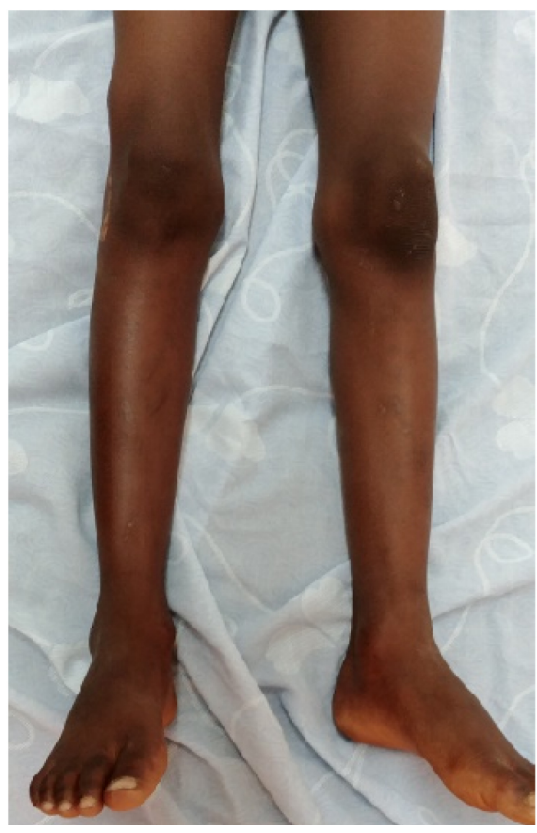

Figure 4. Pelvic long iso limbs.

\section{Discussion}

The definition of the subtrochanteric fracture is variable according to the literature: it extends up to $5 \mathrm{~cm}$ below the little trochanter or for every feature of fracture located over a distance measuring $10 \%$ of the overall length of the femoral diaphysis under the littletrochanter [3] [4] [5] [6]. Few studies show subtrochanteric fractures in the child, and femoral pseudarthrosis in addition [7] [8]. Sun [8] found only one case of pseudarthrosis over 2133 fractures of long bones treated by elastic stable intramedullary nailing (ECMES).

The strict definition of the pseudarthrosis (or non union) rests on three parameters of time, clinical expression and radiological evidence according to De Boeck [2]. A deadline from 6 to 9 months past is necessary since the fracture. The phenomenon of consolidation can be spread out from 4 months to 12 months according to the localization of the fracture and the physiological capacities of healing of the patient. A pseudarthrosis is reflected clinically by pain during loading and abnormal mobility of the fracture site. Radiographic confirmation is provided by the persistence of the fracture characteristics or by the absence of bone callus or periosteal apposition in the form of a bone bridge uniting the fragments.

The bone of the child is solid, dense and in full growth, consequently a fracture is the result of important constraints. The fractures of the upper end of the femur are fractures of high energy, generally associated with other traumas [1] [2] [6] [9].

In a context of polytrauma, the hip fracture can be initially ignored, because all the attention will be drawn to the lesions potentially mortal.

It is a region subject to strong pressure constraints due to the insertion of powerful muscles, whose actions make difficult an anatomical reduction, reduction 
that even when it is obtained, is difficult to maintain outside any osteosynthesis. The traditional displacement of the proximal fragment is done in flexion, abduction and external rotation [2] [3] [6].

Hip fractures in pediatric patients are strongly associated with the occurrence of complications such as avascular necrosis [10], pseudarthrosis and premature closure of the proximal femur growth cartilage resulting in unequal length of pelvic limbs and deformation of the cervico-diaphyseal angle [5] [11].

The nonoperative treatment of fractures is a preferred indication in children because it gives excellent results. However, with respect to subtrochanteric fractures, the occurrence of nonunion is a frequent complication in orthopedic treatment [3] [7] [12]. Even after surgical treatment, the risk of nonunion persists, as well as other complications such as avascular osteonecrosis, delayed consolidation, malunion, growth cartilage lesions and the risk of iterative fracture [1] [3] [13] [14].

In the literature, there is no consensus on treatment, although various methods have been used successfully, including traction or circular plaster, external fixator, plate, stable elastic intramedullary nailing. All of these methods have limitations and potential complications [5] [7] [8]. Diaphyseal and metaphyseal fractures in children are frequently treated with ECMES. We used Kirschner pins as available material. A similar case to our patient has not been reported in the african literature. This can be explained by the rare occurrence of the ailment.

The pediatric proximal femur nail in its indications provides good stabilization with early support in two or three days in case of isolated fracture, excellent bone consolidation and ultimately does not generate limb inequality. Endofixation offers biological, mechanical and technical advantages [6] [11]. Osteosynthesis is made difficult by the small size of the proximal fragment and the proximity of the growth cartilage of the epiphysis. The pins should have good proximal epiphyseal fixation to prevent external rotation of the proximal fragment.

The evolution is favourable and the forecast is excellent if the treatment is surgical, fast and using an endo or exo stable fixing [2] [3] [5] [11].

\section{Conclusion}

The orthopedic treatment of the subtrochanteric fractures of the child is not systematic because it is correlated to a high rate of complications including the pseudarthrosis. The surgical treatment of this pseudarthrosis by endofixation constitutes a satisfactory alternative.

\section{Conflicts of Interest}

The authors declare no conflicts of interest regarding the publication of this paper.

\section{References}

[1] Velazquez, A.D., Capdevila, L.R. and Ponc, R.G. (2016) Fracturas de fémur proximal 
en edadpediátrica. Revista Mexicana de Ortopedia Pediátrica, 1, 14-19.

[2] De Boeck, H. and Scheerlinck, T. (2003) Fracture de l'extrémité supérieur du fémur chez l'enfant. $7 \mathrm{p}$.

[3] Pombo, M.W. and Shilt, J.S. (2006) The Definition and Treatment of Pediatric Sub trochanteric Femur Fractures with Titanium Elastic Nails. Journal of Pediatric Orthopaedics, 26, 364-370. https://doi.org/10.1097/01.bpo.0000203005.50906.41

[4] Segal, L.S. (2000) Custom 95 Degree Condylar Blade for Pediatric Sub Trochanteric Femur Fractures. Orthopaedics, 23, 103-107.

[5] Bimmel, R., Bakker, A., Bosma, B. and Michielsen, J. (2010) Paediatric Hip Fractures: A Systematic Review of Incidence, Treatment Options and Complications. Acta Orthopaedica Belgica, 76, 7-13.

[6] Bedi, A. and Toan Le, T. (2004) Subtrochanteric Femur Fractures. Orthopedic Clinics of North America, 35, 473-483. https://doi.org/10.1016/j.ocl.2004.05.006

[7] Ndour, O., Muzombo, A.M., Ndoye, N.A., Mbaye, P.A., Faye Fall, A., Ngom, G., et al. (2013) Treatment of Femoral Fractures in Children: Indications and Results. About 63 Cases Collected in a Pediatric Surgical Center of Aristide Le Dantec Hospital in Dakar, Senegal. Tunisie Orthopédique, 6, 66-71.

[8] Sun, X.S., Wang, B., Wang, F., Tang, K., Zhanq, Z.Q., Lin, G., et al. (2018) Complications of 2133 Cases of Pediatric Long Bone Fracture Undergoing Elastic Stable Intramedullary Nailing in a Single Medical Center. Chinese Journal of Surgery, 56, 670-676.

[9] Herrera-Soto, A.J., Meuret, R., Philips, H.J. and Vogel, J.D. (2015)The Management of Pediatric Sub Trochanteric Femur Fractures with a Statically Locked Intramedullary Nail. Journal of Orthopaedic Trauma, 29, e7-e11. https://doi.org/10.1097/BOT.0000000000000156

[10] Yeranosian, M., Horneff, J.G., Baldwin, K., et al. (2013) Factors Affecting the Outcome of Adolescent Fractures of the Femoral Neck in Children and Adolescents: A Systematic Review. The Bone \& Joint Journal, 95-B, 135-142. https://doi.org/10.1302/0301-620X.95B1.30161

[11] Prentice, H.A., Paxton, E.W., Hunt, J.J., Grimsrud, C.D. and Weiss, J.M. (2017) Pediatric Hip Fractures in California: Results from a Community-Based Hip Fracture Registry. The Permanente Journal, 21, 16-081. https://doi.org/10.7812/TPP/16-081

[12] Souna, B., Shoeschman, P. and Dodo, D.G.R. (2006) Fracture diaphysaire fermée du fémur (FDFF) chez l'enfant et l'adolescent: épidémiologie, évaluation du traitement et du coût à l'hôspital national de Niamey (HNN) (à propos de 106 cases). Revue Marocaine de Chirurgie Orthopédique et Traumatologique, 28, 30-33.

[13] Lasommbes, P., Nespola, A., Poircuitte, J.M., Popkov, D., De Gheldere, A., Haumont, T., et al. (2012) Early Complications with Flexible Intramedullary Nailing in Childhood Fracture: 100 Cases Managed with Precurved Tip and Shaft Nails. Orthopaedics and Traumatology: Surgery and Research, 98, 369-375. https://doi.org/10.1016/j.otsr.2011.11.011

[14] Metezeau, J.P. (2006) Fractures de la diaphyse fémorale chez l'enfant. EMCAppareil Locomoteur, 20, 14B-10. https://doi.org/10.1016/S0246-0521(06)41696-X 